\title{
A produção de documentário no Rio Grande do Sul na visão dos realizadores*
}

\author{
Cássio dos Santos Tomaim** \\ Dieison Marconi**** \\ Marília Dalenogare*****
}

\section{Resumo}

Em um universo de mais de 70 realizadores audiovisuais identificados em um mapeamento que buscou catalogar a produção de documentários no Rio Grande do Sul entre os anos de 1995 e 2010, foram selecionados 11 documentaristas para que, a partir de entrevistas semi-estruturadas, pudéssemos compreender quem são e o que pensam sobre a produção, distribuição e exibição do documentário no Brasil. A maioria dos realizadores entrevistados têm formação em cursos de Jornalismo em universidades públicas e particulares do Rio Grande do Sul, onde conheceram e se envolveram com o cinema e o audiovisual. É consenso entre os realizadores que a escassez de recursos para a produção é ainda um complicador

* Este artigo traz os resultados da pesquisa "Documentário gaúcho contemporâneo: memória e identidade (1995-2010)", financiada pelo Edital Universal CNPq 014/2009. Contribuíram para as entrevistas com os realizadores, Neli Mombelli, Josafá Rhode e Marciane Hences.

** Professor doutor do Programa de Pós-Graduação em Comunicação (PPGCOM) e do Programa de Pós-Graduação em História (PPGH) da Universidade Santa Maria (UFSM), Santa Maria-RS, Brasil, e do Departamento de Ciências da Comunicação (Cesnors) da Universidade Federal de Santa Maria (UFSM) / campus de Frederico Westphalen, Frederico Westphalen-RS, Brasil. E-mail: tomaim78@gmail.com

*** Estudante do Curso de Jornalismo do Departamento de Ciências da Comunicação (Cesnors) da Universidade Federal de Santa Maria (UFSM) / campus de Frederico Westphalen. Frederico Westphalen-RS, Brasil. E-mail: dieisonmarconi@gmail.com

**** Estudante do Curso de Jornalismo do Departamento de Ciências da Comunicação (Cesnors) da Universidade Federal de Santa Maria (UFSM) / campus de Frederico Westphalen. Frederico Westphalen-RS, Brasil. E-mail: mariliadalenogare@hotmail.com 
para o desenvolvimento do gênero no Estado e no Brasil, porém, reconhecem que a dependência às leis de incentivos fiscais não é saudável para uma produção que se pretende independente, como é o caso do documentário.

Palavras-chave: Documentário gaúcho. Perfil. Cineastas. Produção. Exibição.

\section{The documentary production in Rio Grande do Sul in the vision of the filmmakers \\ Abstract}

Between the years 1995 and 2010 it was conducted a mapping that identified at least 70 audiovisual producers of documentaries in the state of Rio Grande do Sul Among these, 11 filmmakers were interviewed in order to understand who they are and what they think about the production, distribution and screening of the documentary in Brazil. The semi-structured method was used to conduct the interviews that allowed to realize that most of the directors has a background in journalism courses at public and private universities of Rio Grande do Sul, where they became familiar with the language of cinema and audiovisual. The consensus among the filmmakers is that the dearth of resources for production remains a complicating factor for the development of this kind of movie both in the state, as in Brazil. They recognize, however, that the dependence of tax incentive laws is not healthy for a production that aims to be independent, as is the case of the documentary.

Keywords: Documentary in the state of Rio Grande do Sul. Profile of the documentarians. Filmmakers. Documentary production. Film viewing.

\section{La producción de documentales en Rio Grande do Sul, en la visión de los cineastas}

\section{Resumen}

En el conjunto de más de 70 cineastas audiovisuales identificados en una cartografía que tuvo por finalidad catalogar la producción de documentales en el estado brasileño del Rio Grande do Sul entre los años 1995 y 2010, han sido seleccionados 11 documentalistas para que, por medio de entrevistas semiestructuradas, pudiéramos entender quiénes son y qué piensan sobre la producción, distribución y exhibición de películas documentales en Brasil. La mayoría de los cineastas son periodistas egresos de universidades públicas y particulares del Rio Grande do Sul, donde han conocido la práctica de cine y se han involucrado con la producción audiovisual. Es consenso entre los cineastas que la escasez de fomentos para la producción todavía es un obstáculo para el desarrollo del género en el estado y en Brasil, sin embargo reconocen que la dependencia de los subsidios obtenidos por medio de leyes de incentivo con recursos fiscales no es positivo para un producto cinematográfico que aspira la independencia. Palabras clave: Documental de Rio Grande do Sul. Perfil. Cineastas. Producción. Exhibición. 


\section{Introdução}

$\mathrm{N}$ o Rio Grande do Sul, entre os anos de 1995 e 2010, foram produzidos 96 documentários, conforme foi possível identificar a partir de um mapeamento em fontes documentais como catálogos e anais de festivais, dicionários de filmes, livros e bancos de dados de outras pesquisas, assim como da Cinemateca Brasileira. Dados que depois foram confrontados com informações complementares, a partir de uma consulta direta feita as produtoras de audiovisual do Estado. Um formulário eletrônico foi enviado para 28 produtoras previamente identificadas pela pesquisa, 39,28\% (11) destas retornaram o contato. Como todo trabalho de mapeamento é contínuo, reconhecemos que os resultados obtidos até o momento são parciais, pois novos dados vão surgindo diariamente, conforme uma nova fonte é consultada. Entretanto, como toda pesquisa tem suas limitações metodológicas e se faz necessário avançar para novas fases, compreende-se que os dados catalogados se constituem numa amostra confiável do cenário da produção de documentários no Rio Grande do Sul, no período estudado.

Ainda a respeito deste trabalho de mapeamento, é importante destacar que as produções do Rio Grande do Sul referentes ao DOCTV, programa de fomento à produção de documentários do Ministério da Cultura, e as séries de documentários do Núcleo de Especiais da RBS TV, emissora gaúcha afiliada à Rede Globo de Televisão, não foram catalogadas por se tratar de produções não ficcionais realizadas exclusivamente para exibição televisiva, que seguem editais, regras e contratos específicos, e que no nosso entendimento merecem um estudo mais detalhado.

Diante dos dados percebe-se que nestes 15 anos a produção de documentários no RS apresenta uma linha descontínua, com altos e baixos, porém, é possível reconhecer um crescimento principalmente a partir de 2004. Em 2007, foram produzidos quatro longas-metragens dos sete documentários realizados no Estado, mas no ano seguinte este número mais que duplicou, foram 18 
documentários entre curtas, médias e longas-metragens. Números que acompanham o desempenho da produção documentária no cenário nacional no mesmo período. Em 2002, ocorreu o que se convencionou denominar de "boom do documentário brasileiro" em que uma fatia de $40 \%$ de toda a produção cinematográfica do país foi destinada a este gênero, com dez filmes de longa-metragem produzidos, sendo que, em 2007, chegamos a 32 documentários exibidos na grande tela. Segundo Maruno, este cenário pode ser descrito da seguinte maneira:

No caso do ano 2002, pode-se relacionar o período de queda nas captações e, portanto, os baixos valores em circulação, como um dos fatores que impulsionaram o número de documentários lançados. Já no caso de 2007, não houve queda no total de captação de valores, mas sim aumento na porcentagem de valores dedicada ao gênero, ou seja, uma divisão de valores em que o documentário saiu em vantagem (MARUNO, 2008, p.48-49).

Já a respeito dos realizadores gaúchos, notou-se que um grande número fez apenas um único documentário nos últimos 15 anos. Dos 79 realizadores catalogados, menos de 30\% apresentaram uma produção contínua, com mais de um filme realizado no período estudado. Outro dado que nos chamou a atenção é a contribuição feminina a esta produção contemporânea. As cineastas gaúchas têm demonstrado uma produção mais contínua ao longo do período analisado, apesar dos homens serem ainda responsáveis pela maioria dos documentários produzidos no Estado (70\%).

Para compreendermos melhor este cenário, procuramos por meio de entrevistas semi-estruturadas com os realizadores identificar suas experiências no tocante a sua obra e à produção regional e nacional de documentários. $\mathrm{O}$ artigo tem como objetivo levantar o perfil artístico-cultural do documentarista gaúcho, suas influências e tendências, e qual a relação de seus trabalhos com as produções de não ficção do país. Quem são e o que pensam estes realizadores sobre a produção, distribuição e exibição de documentários no Rio Grande do Sul e no Brasil?

Para a seleção dentro de um universo de mais de 70 realizadores catalogados foi definido um método que estabeleceu o 
cruzamento entre os dados de três categorias: (1) longa-metragem: apesar de não ser o formato que predomina na produção de não- ficção do Estado, foi levado em consideração que este é o formato de maior vitrine para a produção cinematográfica; (2) premiações: por permitir uma maior visibilidade e prestígio aos filmes e seus realizadores para além do Estado do Rio Grande do Sul - por outro lado esta categoria possibilita contemplar documentaristas que produziram para além do formato longa-metragem, já que a maioria dos festivais nacionais e os internacionais abrem espaço para o curta e o média-metragem; e (3) produção contínua (mais de um filme): contemplar os realizadores que mantiveram uma produção contínua no período estudado. Em um primeiro momento, o cruzamento forneceu os nomes de dez cineastas, mas se resolveu contemplar outros dois realizadores em função de manterem uma produção contínua de três filmes no período estudado e por suas produções estarem vinculadas às produtoras localizadas fora da capital gaúcha, Santa Maria e Caxias do Sul.

No final foram entrevistados 11 realizadores, sendo que com apenas um não conseguimos contato durante a fase de pesquisa. Os selecionados possuem formação, tendências e relações diversas com o documentarismo, além de suas produções refletirem um cenário regional mais amplo. A partir desta seleção temos cineastas que na última década têm apresentado uma produção contínua de documentários com focos diversos, assim como realizadores experientes responsáveis pelos principais sucessos e pela visibilidade do cinema de não ficção do Rio Grande do Sul no período estudado.

\section{Os realizadores entrevistados foram:}

1. Carolina Berger: 32 anos, roteirista e diretora, formada em Jornalismo pela Universidade Federal de Santa Maria (UFSM) em 2001. Herança (2007) rendeu-lhe os prêmios de melhor documentário curta-metragem, na categoria Vídeo Nacional Independente no XV Gramado Cine Vídeo, melhor filme e melhor direção na Mostra Competitiva Santa Maria e Região do VI Santa Maria Vídeo e Cinema. Outros documentários da diretora produzidos no 
período estudado: Versões (2005) e Dias no tempo (2010).

2. Flávia Seligman: 43 anos, roteirista e diretora, formada em Jornalismo pela Pontifícia Universidade Católica do Rio Grande do Sul (PUC-RS) em 1986, Mestre e Doutora em Cinema pela USP. Atualmente é professora do Curso de Realização Audiovisual da Universidade do Vale do Rio dos Sinos (UNISINOS). Entre suas produções estão os documentários Um dia no mercado (1998), Ilhas Urbanas (2005) e Certos Olhares (2008).

3. Gustavo Spolidoro: 40 anos, cursou Publicidade e Propaganda em 1996 na PUC-RS, onde fez o Mestrado em Comunicação e atua como professor do Curso Superior de Tecnologia em Produção Audiovisual. Entre suas produções estão os documentários Maré vermelha (2001), Gigante: como o Inter conquistou o mundo (2007) e De volta ao quarto 666 (2008).

4. Jaime Lerner: 53 anos, formado em Cinema e TV em Israel, em 1983, leciona na PUC-RS, no curso de especialização em Produção Cinematográfica. De 2009 a 2011 foi presidente da Associação Profissional de Técnicos Cinematográficos do Rio Grande do Sul (APTC), seccional gaúcha da ABD (Associação Brasileira de Documentaristas e Curtametragistas). Atualmente é conselheiro da SAV - Secretaria do Audiovisual do Ministério da Cultura. Destaque para os documentários Porto Alegre, meu canto no mundo (2007) e Harmonia (2000), primeiro documentário em longa-metragem no Rio Grande do Sul depois de décadas sem o registro de produções não ficcionais neste formato no Estado.

5. Liliana Sulzbach: 47 anos, formada em Jornalismo e Publicidade e Propaganda. Mestre em Ciência Política pela UFRGS. Trabalha como diretora, roteirista e produtora desde 1992. Estreou no longa-metragem em 2004 com o documentário $O$ cárcere e a rua, filme premiado como melhor documentário em vários festivais nacionais e internacionais, dentre eles o 32ํ Festival de Gramado, o Festival 
do Filme Documentário e Etnográfico de Belo Horizonte e o Festival Internacional El Ojo Cojo, na Espanha. O seu documentário em curta-metragem $\mathrm{A}$ invenção da infância (2000) também foi amplamente premiado no Brasil e no exterior. Trabalhou como produtora independente para a Hamburger Kino Kompanie/Hamburgo, para a M. Schmiedt Produções e para a Spiegel TV Alemanha, onde realizou diversos documentários.

6. Lissandro Stallivieri: 39 anos, é formado em Jornalismo na Universidade de Caxias do Sul (1998). Trabalhou durante oito anos como jornalista e em 2003 fundou a produtora Spaghetti Filmes. Entre suas produções no período estudado estão os documentários em média-metragem Velhos heróis (2004), A montanha do sonho imigrante (2004), Trilhos do trem (2006) e o curta-metragem Al cinema (2010).

7. Luiz Alberto Cassol: 43 anos, é formado em Biologia. Atualmente, é o diretor do IECINE-RS e da Cinemateca Paulo Amorim, além de presidir o Conselho Nacional de Cineclubes Brasileiros e produtor delegado do Brasil no Fórum Entre-Fronteiras. Foi um dos fundadores do Festival Santa Maria Vídeo e Cinema. Dentre os documentários que realizou destaque para Águas dançantes (1998), Super 70 (2006) e Faltam cinco minutos (2007).

8. Marcos Borba: 32 anos, é formado em Jornalismo pelo Centro Universitário Franciscano (UNIFRA) e atualmente é Mestrando do Programa de Pós-Graduação em Comunicação da UFSM. Foi um dos precursores da TV OVO, criada em Santa Maria em 1996, e que hoje atua como mídia comunitária visando a formação profissional de jovens de bairros periféricos da cidade por meio do audiovisual. Suas principais realizações no período estudado foram os documentários Avenida Progresso (2009) e 1ํ Quadra (2009), que recebeu o Prêmio Cultura Viva e menção honrosa no VIII Santa Maria Vídeo e Cinema.

9. Monica Schmiedt: 52 anos, produz filmes desde os anos de 1980. Começou a dirigir documentários em 1997 e 
desde então exerce as duas funções. Estudou Arquitetura e História e já produziu teatro e música. Em 1994, abriu a M. Schmiedt Produções, realizadora de filmes para cinema e televisão. Como diretora e produtora, realizou três documentários, Antártida, o último continente (1997), Doce Brasil holandês (2010) e Extremo sul (2004, co-dirigido com Sylvestre Campe).

10. René Goya Filho: 43 anos, formado em Jornalismo pela UFSM. Desde 1997 vem trabalhando com documentários, ano em que criou a produtora Estação Elétrica Filme e Vídeo, que tem se destacado na produção de documentários com foco na música regional do Rio Grande do Sul. Criadores do Brasil (2005), Fandango (2008) e Origens (2010) são suas principais realizações no período estudado.

11. Tabajara Ruas: 70 anos, formou-se em Arquitetura na UFRGS e estudou Cinema na High School de Vejle, na Dinamarca, durante o seu exílio político entre os anos de 1971 a 1981. Cineasta e escritor, reside atualmente em Florianópolis (SC). Dentre seus filmes mais conhecido está o longa-metragem Brizola- Tempos de Luta (2007), documentário premiado como melhor montagem no Cine-PE - Festival do Audiovisual em 2008.

\section{Quem são e como pensam os realizadores gaúchos}

A respeito do perfil do documentarista gaúcho, nota-se, curiosamente, que $63 \%$ dos entrevistados são oriundos dos Cursos de Comunicação Social das universidades públicas e privadas do Rio Grande do Sul, sendo que seis deles são formados em Jornalismo. Isto nos leva a concluir que a maioria dos realizadores teve o seu primeiro contato com o cinema e com o documentário na universidade, a partir de oficinas, cursos, grupos e laboratórios de produção, sessões de cineclubismo etc. Somente dois documentaristas têm formação em Cinema e ambos fora do Brasil, em Israel e Dinamarca. É o caso de Jaime Lerner que se interessou por cinema aos 13 anos em Israel, quando sua escola recomendou-lhe para um 
curso de cinema extracurricular. Já Tabajara Ruas, escritor e cineasta, foi se interessar pela área quando esteve exilado nos anos de 1970 na Dinamarca, ao estudar cinema na High School de Vejle.

Esta relação dos realizadores gaúchos com os cursos de Jornalismo do Rio Grande do Sul se explica pelo surgimento tardio de cursos superiores na área de Cinema no Estado, sendo o primeiro criado somente em 2003 pela UNISINOS. Monica Schmiedt é a única realizadora, dentre os entrevistados, que teve origem no movimento gaúcho de superoitista dos anos de 1980, participando da produção de filmes como Verdes Anos, Me beija e Aqueles Dois. O início no documentário se deu mais tarde a partir do seu interesse em fazer um projeto autoral. Já Marcos Borba, um dos mais jovens dos documentaristas entrevistados, é o único dos realizadores que se profissionalizou depois de participar de oficinas de audiovisual para jovens das periferias de Santa Maria realizadas pela TV OVO. Segundo Borba ${ }^{1}$, foi natural o seu interesse e da equipe da TV OVO pelo documentarismo: "[...] a TV OVO trabalha com a realidade, porque ela nasceu num contexto de periferia, tinham demandas nas regiões onde ela trabalhou que precisavam estar em foco pelas câmeras destes adolescentes".

Questionados sobre os formatos de seus documentários, um ou outro realizador declarou que a opção pelo curta, ou média ou o longa-metragem é uma questão de estética, entretanto a maioria foi enfática ao afirmar que a escolha se dá mesmo em função dos recursos e financiamentos disponíveis para a produção. Segundo o mapeamento realizado, entre 1995 e 2010, 53\% dos documentários produzidos no Estado são média-metragem, seguidos do curta-metragem (31\%) e do longa-metragem (13\%). Dizem os realizadores que o predomínio do média-metragem, seguido do curta metragem, é explicado pelas exigências dos editais de fomento, sejam os municipais, estaduais e federais, que priorizam estes formatos pelo baixo orçamento a ser captado e pelo curto tempo que exigem para a produção.

Por outro lado, há cineastas que preferem o média-metragem para atender ao mercado televisivo. "O média-metragem tem uma

\footnotetext{
${ }^{1}$ Entrevista de Marcos Borba concedida a Neli Mombelli em 05 de agosto de 2011. Santa Maria/RS.
} 
vantagem, ele tem a minutagem da televisão, a grade da televisão aceita melhor média-metragem de até 52 minutos do que os curtas, por exemplo, e mesmo do que os longas", explicou Schmiedt ${ }^{2}$. No caso dos curtas-metragens, a escassez de recursos é fator preponderante nas produções, o que se agrava ainda mais no interior do Estado onde não há uma cultura da iniciativa privada em financiar projetos artísticos e culturais, dificultando a captação de recursos. $\mathrm{Na}$ visão de Borba, na mesma entrevista, as produções no interior estão reféns do "tempo limite" dos editais:

Santa Maria [...] tem ótimas histórias que renderiam ótimos longas metragens. Mas não se tem tanto o apoio de captação de recursos para se manter um projeto de longa duração. [...] Não é descartada essa possibilidade, mas a produção do curta ocorre justamente por essa facilidade de produzir e trabalhar num tempo limite, que é o tempo dos editais, que é de um ano.

Já para Lissandro Stallivieri, da Spaghetti Filmes de Caxias do Sul, uma das produtoras com maior número de documentários produzidos no Estado a partir de 2004, a opção pelos curtas e médias pode ser uma questão de estratégia para se conhecer o mercado audiovisual tanto regional quanto nacional. Mas há quem defenda que a questão estética pesa na hora de fazer a escolha pelo formato, é o caso de Jaime Lerner’: "Eu não sigo uma regra, mas eu penso que é muito difícil produzir um documentário de curta metragem. Isso porque os temas dos documentários devem ser aprofundados, devem expor os processos, e tudo isso é tempo de tela". Entretanto, o cineasta reconhece que "Por outro lado, é uma questão econômica também, ao mesmo tempo em que o documentário é mais difícil de captar, é mais barato de filmar, então fica mais fácil produzir um longa documentário do que um longa de ficção."

\footnotetext{
${ }^{2}$ Entrevista de Monica Schmiedt concedida a Marília Dalenogare em 07 de outubro de 2011. Porto Alegre/RS.

${ }^{3}$ Entrevista de Jaime Lerner concedida a Marciane Hences em 08 de outubro de 2011. Porto Alegre/RS.
} 


\section{Produção x distribuição/exibição}

Apesar do mapeamento ter demonstrado que a produção de documentário no Estado tem sobrevivido nos últimos 15 anos sobretudo graças às leis de incentivo, fato esse comprovado pelos dados, em que 38\% dos filmes são realizados com o apoio da Lei de Incentivo Cultural (LIC) tanto municipal, estadual e federal, a maior dificuldade apontada pelos cineastas gaúchos é ainda a escassez de recursos. Para Carolina Berger, depender de financiamentos atrelados ao Estado é um sério problema para a vitalidade do documentário no Rio Grande do Sul, uma vez que os realizadores encontram limitações para as suas produções. É o caso da LIC que, na opinião da realizadora de Santa Maria, prioriza alguns temas com apelo comercial.

[...] o fundo de Incentivo à Cultura (LIC), é muito conservador no sentido de conceito, os critérios de seleção priorizam muito alguns temas em detrimento de outros, tem muito apelo comercial também. Eu acho que teria que trabalhar mais com ideias que tenham mais conteúdo, no sentido de se buscar renovar a linguagem. Muitos projetos são aprovados em função do tema que tratam e não pela estética ${ }^{4}$.

Para Tabajara Ruas, o desafio está em convencer a iniciativa privada em investir recursos no documentário, em um tipo de cinema que é menos entretenimento e mais educativo, engajado no mundo. A saída para ele é "[...] ter uma política para trazer o público pra ver filmes de mais qualidade, porque basicamente o documentário não é diversão, dificilmente as pessoas vão ver um documentário para dar risada. O documentário na verdade é uma reflexão sobre a sociedade" ${ }^{5}$.

Ainda segundo o escritor e cineasta, já houve uma época no Rio Grande do Sul que se podia falar em uma tradição na produção de documentários, hoje é diferente. Sem contar que as diferenças

\footnotetext{
${ }^{4}$ Entrevista de Carolina Berger concedida a Marciane Hences em 11 de maio de 2011. Santa Maria/RS.

${ }^{5}$ Entrevista de Tabajara Ruas concedida a Dieison Marconi em 08 de novembro de 2011. Santa Maria/RS.
} 
culturais da região têm sido pouco exploradas pelo documentarismo contemporâneo, um sufocamento na produção de não-ficção que Ruas atribui à televisão. "Nós temos uma quantidade enorme de diferenças regionais dentro do Estado, jeito de falar, de música, de etnia mesmo, e se vê muito pouco disso. Acho que a TV sufoca um pouco o documentário". Os dados demonstram que temas como Imigração (7\%), Questões étnicas (4\%), Cultura, artes e festas populares (2\%) e Campo/Rural (1\%) não estiveram entre as preferências dos realizadores gaúchos. Tão pouco a temática Tradição Gaúcha, tendo em vista que em quase 100 documentários sequer um filme tratou do assunto de forma direta. Harmonia (2000) de Jaime Lerner é o documentário do período analisado que mais próximo tocou o tema do tradicionalismo gaúcho ao retratar o conflito entre o Movimento Tradicionalista Gaúcho (MTG) e os carnavalescos em torno da ocupação do parque Harmonia, na região central de Porto Alegre.

Então, ao encontro da fala de Ruas, nota-se que o documentário contemporâneo do Rio Grande do Sul tem se interessado muito por temas urbanos, aspecto que pode encontrar explicação no fato da maioria das produtoras estarem localizadas na capital Porto Alegre. Já a produção televisiva do Estado, liderada pelo Grupo RBS de Comunicações, tem se dedicado a consolidar no imaginário coletivo regional o mito do "ser gaúcho", imagem ancorada nas tradições e memórias culturais do MTG (Movimento Tradicionalista Gaúcho) ${ }^{6}$.

Ainda a respeito dos incentivos, Flávia Seligman ${ }^{7}$ destaca que o problema é que não existe legislação específica para a produção de documentários no Rio Grande do Sul, mas reconhece que a parceria cinema/televisão é imprescindível para garantir a exibição

\footnotetext{
${ }^{6}$ Este aspecto das produções do Núcleo de Especiais da RBS TV está na dissertação "A Conquista do Oeste/RBS TV: memória e identidade gaúcha na fronteira oeste brasileira", de Priscila Ferreira, defendida em 2012 no Programa de Pós-Graduação em História da Universidade Federal de Santa Maria (UFSM). ${ }^{7}$ Entrevista de Flávia Seligman concedida a Josafá Rohde em 03 de novembro de 2011. Porto Alegre/RS.
} 
dos documentários. Gustavo Spolidoro ${ }^{8}$ também concorda que o problema é financeiro, apesar de acreditar que

[...] hoje em dia é muito fácil fazer documentário. [...] Na verdade, as portas estão mais abertas pra fazer documentário do que para a ficção, porque nos editais que contemplam a ficção também tem verba e espaço pra fazer documentário, só que também têm editais só pra documentário. A RBS TV tem muitos projetos de documentário, é um caminho bem legal que a gente tem feito ${ }^{9}$.

Para concluir o debate sobre o financiamento público, Stallivieri reconhece que não é saudável para a produção independente de documentário a dependência às leis de incentivos fiscais, mas acredita que isto faz parte do próprio amadurecimento dos documentaristas no Estado e das produtoras de médio porte, como é o caso da Spaghetti Filmes:

[...] a gente enxerga o comportamento de vários realizadores e produtoras independentes que às vezes acabam fazendo um filme só ou dois, e que a gente brinca que o cara está brincando de fazer cinema ou está se aventurando mesmo a fazer um filme. Porque talvez não tenha essa estrutura de se manter na indústria cinematográfica ${ }^{10}$.

Isto vem ao encontro do cenário com o qual deparamos em nosso mapeamento, em que $72 \%$ dos documentaristas catalogados produziram somente um filme durante o período estudado, fortalecendo a tese de que a produção não ficcional no Estado, nos últimos 15 anos, esteve dependente das leis de incentivo fiscais federais, estaduais e municipais, além do vídeo digital e das novas tecnologias terem favorecido as produções de baixo orçamento, sendo que $60 \%$ dos documentários foram produzidos no suporte

\footnotetext{
${ }^{8}$ Entrevista de Gustavo Spolidoro concedida a Dieison Marconi em 06 de outubro de 2011. Porto Alegre/RS.

${ }^{9}$ Desde 1999 o Grupo RBS de Comunicações, por meio do seu Núcleo de Especiais da RBS TV, emissora afiliada à Rede Globo, tem sido responsável por uma produção regular do documentário regional e, consequentemente, da sua difusão na TV aberta brasileira.

${ }^{10}$ Entrevista de Lissandro Stallivieri concedida a Cássio dos Santos Tomaim em 05 de setembro de 2010. Caxias do Sul/RS.
} 
de vídeo digital, enquanto que $12 \%$ se valeram do $35 \mathrm{~mm}$. Uma constatação que encontra ressonância nos depoimentos de produtores e diretores entrevistados por Trindade (2011, p.274), que acreditam que o boom do documentário e a consequente exibição destes filmes nas salas de exibição estão diretamente associados às novas tecnologias e às leis de incentivo que, contraditoriamente, obrigam que estes documentários tenham uma cópia em película para exibição na grande tela, enquanto que o circuito exibidor brasileiro utiliza na sua maioria de projetores digitais.

A produção em suporte de vídeo digital tem possibilitado aos documentaristas concorrem a editais que preveem orçamentos de baixo custo para a realização de curtas e médias metragens, tanto do gênero ficção quanto documentário. Uma brecha que explica o aumento gradativo da produção de documentários no Estado do RS, a partir de 2004, mas que traz outro componente: o número expressivo de realizadores audiovisuais que produziram um único documentário em 15 anos. Os editais têm fomentado a produção, cumprido com o seu objetivo primário, mas os resultados destas produções não têm tido reflexo na manutenção da maioria destes documentaristas na indústria cinematográfica, sejam eles aventureiros ou não.

Isto nos remete a outro complicador para a produção de documentários no Estado do RS: a distribuição/exibição. Segundo o mapeamento realizado, 31\% dos documentários foram exibidos em festivais e $20 \%$ em salas de cinema alternativo (cineclubes, associações, museus, universidades etc), não chegando ao circuito de exibição comercial que alcança o grande público do cinema brasileiro. Uma situação que frustra cada vez mais o realizador, que se vê preso a encontrar outras soluções, como ressalta René Goya Filho: "Às vezes, a dificuldade é mais na exibição do que na produção, porque tu produz algo que ninguém vê. Então, tu acaba colocando na internet. [...] Claro, que poderia ter um canal mais efetivo de exibição, e até de encontro de discussão com essas pessoas [o público] ${ }^{11}$ ".

${ }^{11}$ Entrevista de René Goya Filho concedida a Dieison Marconi em 07 de outubro de 2011. Porto Alegre/RS. 
A distância do centro das decisões políticas da área do audiovisual e a falta de infraestrutura e de profissionais também são apontados por alguns cineastas como dificuldades enfrentadas por eles. Para Luiz Alberto Cassol, “[...] a gente precisa, e me parece que está surgindo cada vez mais cursos específicos na área de documentário. [...] Faltam mais cursos ${ }^{12 ” . ~ S e g u n d o ~ e l e, ~ j a ́ ~ h a ́ ~}$ iniciativas de algumas universidades do Estado neste sentido, mas é preciso profissionalizar o segmento de produção de documentários, constatação válida não só para o Rio Grande do Sul, mas para todo o Brasil. As iniciativas existem, mas ainda são tímidas. No Estado da Bahia, na recém criada Universidade Federal do Recôncavo Baiano, desde 2008 funciona o Curso de Cinema e Audiovisual, com ênfase em documentário.

Outro ponto que foi consenso entre alguns realizadores entrevistados diz respeito à necessidade de ampliar o intercâmbio entre os documentaristas do Estado para que possam refletir sobre as suas produções. Carolina Berger é enfática ao afirmar que "[...] falta engajamento mais profissional dos cineastas gaúchos que se fecham em um pequeno círculo ${ }^{13}$ ". Já para Borba, a troca de experiência entre os realizadores seria uma forma de surgir ações e projetos coletivos concretos, como criar um circuito de exibição para os documentários produzidos no Estado, além de unir forças para pressionar por mais editais de fomento à produção de documentários.

\section{Regional versus nacional}

Alguns realizadores se permitiram fazer uma relação entre seus filmes e o cenário nacional do documentário brasileiro. É o caso de Berger que reconhece que suas obras se filiam aos aspectos de maturidade e criatividade dos atuais documentários produzidos no país, mas que fogem à regra. "[...] são filmes mais lentos, não tratam de grandes eventos, não são grandes conflitos, nem temas polêmicos, que geralmente são tratados pelos cineastas brasilei-

${ }^{12}$ Entrevista de Luiz Alberto Cassol concedida a Neli Mombelli em 04 de agosto de 2011. Santa Maria/RS.

${ }^{13} \mathrm{Na}$ entrevista já citada. 
ros”. Já Liliana Sulzbach assume, em entrevista, que seus filmes se relacionam com uma tradição nacional de documentário de cunho social e revela que "até gostaria de sair um pouco disso".

A temática musical tem aproximado os documentários da Estação Elétrica Filme e Vídeo de um aspecto da produção nacional, uma vez que tem aumentado os documentários musicais no Brasil nos últimos anos. Para Goya Filho ${ }^{14}$, a opção por este tema nasceu da própria necessidade regional.

Aqui a gente não tem um olhar para nossas músicas, e aí eu me senti meio que numa missão quando comecei nisso, tem que dar uma cara, um jeito, um olhar pra essa música que é feita aqui, essa conexão com o mundo platino do Uruguai e da Argentina, esse modo da gente ser... ser periférico e quase chegar lá no Brasil.

Já a produção não ficcional da TV OVO, em Santa Maria, dialoga com uma preocupação coletiva com a memória, em que o barateamento e a popularização do vídeo digital contribuíram para tornar o documentário o meio mais apropriado para o registro desta memória, por meio do uso de testemunhos orais. Dentre os realizadores de mídias comunitárias é comum a opção pelo gênero documentário, em geral pelo custo da produção ser menor em comparação aos produtos ficcionais. No entanto, este não aparenta ser o principal motivo, hoje em dia, que levam jovens realizadores de bairros periféricos de inúmeras cidades do Brasil a se envolverem com a produção audiovisual. Eles encontram no documentário uma forma de expressão das histórias, das memórias, das identidades de suas comunidades, são produções que, apesar de técnica e esteticamente simples, são realizadas com uma vontade de memória que se resume em não deixar que o passado histórico de suas cidades, comunidades, seja esquecido; são produtos de resistência frente a políticas frágeis ou inexistentes de preservação de patrimônios culturais materiais e imateriais ${ }^{15}$. Segundo Borba, a TV OVO se

${ }^{14} \mathrm{Na}$ entrevista já citada.

15 Para mais informações sobre a TV OVO e a produção de documentários no contexto do audiovisual comunitário em Santa Maria consultar a dissertação de Neli Mombelli, intitulada "Santa Maria projetada: memória e identidade nos documentários da TV OVO”, defendida em 2012 no Programa de Pós-Graduação em Comunicação da UFSM. 
identifica com o cenário do documentário brasileiro na medida em que há cada vez mais pessoas interessadas na preservação da memória, que há projetos nacionais como o do Museu da Pessoa responsável por "guardar" as histórias de pessoas comuns. "Quando a TV OVO começou a produzir com essa intenção de recuperação da memória a gente viu que existia uma lacuna na cidade e nos demos conta de que seria um papel importante para nossa comunidade e a cidade como um todo ${ }^{16 "}$.

Ainda a respeito de como os realizadores gaúchos localizam suas produções no cenário brasileiro, Stallivieri reconhece que suas produções não têm tido destaque fora do circuito regional, entretanto é enfático ao afirmar que a Spaghetti Filmes mudou o mercado audiovisual do documentário em Caxias do Sul, um fenômeno que ele acredita não ser apenas local, mas que deve se repetir em todo o Brasil e no mundo devido ao acesso às novas tecnologias, "[...] de você ter acesso a uma câmera boa e a possibilidade de realizar isso e editar no seu computador. Então, acho que essa explicação é real. E acho que a Spaghetti Filmes de 2004 para cá faz parte desse movimento todo que está acontecendo não só no Brasil, mas em vários lugares do mundo ${ }^{17}$ ".

A produção de documentários no Rio Grande do Sul é marcada por olhares femininos e masculinos, os homens correspondem a $70 \%$ dessa produção, no entanto, são elas - as diretoras - que possuem uma produção mais contínua e mais reconhecida no circuito gaúcho e nacional, tendo seus filmes destacados em festivais e salas de exibição pelo Brasil. Questionadas a respeito de um "olhar feminino" na recente produção não ficcional do Estado, a maioria das cineastas entrevistadas negou qualquer relação dos seus filmes com uma perspectiva única, seja na temática, seja na estética. Sulzbach prefere pensar que a presença feminina na produção do audiovisual do Estado tem levado cada vez mais as gaúchas a realizarem seus próprios filmes. "Eu acho que aqui no Rio Grande do Sul a mulher tem uma tradição em fazer produção audiovisual, então ela conhece os caminhos, os percalços de buscar

\footnotetext{
${ }^{16} \mathrm{Na}$ entrevista já citada.

${ }^{17} \mathrm{Na}$ entrevista já citada.
} 
os recursos pra produzir e dessa forma acaba também produzindo e dirigindo seus próprios documentários ${ }^{18}$ ". Analisando sua obra, Schmiedt afirmou enfaticamente que nunca buscou uma temática feminina, "Acho que existe um olhar individual, o olhar do realizador em qualquer filme documentário [...] seja ele masculino ou feminino. Não existe uma temática feminina, não tenho essa preocupação e não levanto essa bandeira tampouco, porque isso seria mais machista do que qualquer outra coisa". Mas a realizadora não negou que seus filmes são resultados de uma experiência feminina, um ponto de vista de uma mulher no e sobre o mundo: "[...] evidentemente, que eu tenho a minha experiência, a minha experiência é a experiência de uma mulher. Então, nesse sentido sim existe uma diferença de vivência, mas todos os meus filmes poderiam ser feitos por um homem. Para Seligman, pensar em um "olhar feminino" pode ser uma questão limitadora; ele prefere acreditar que se tem algo que difere sua produção dos demais realizadores, homens ou mulheres, é a militância que, segundo ela, é particular da sua geração:

A gente tem um olhar militante. E isso é uma coisa da minha geração, não da geração atual [...]. A gente tem um outro olhar sobre o passado, principalmente sobre o passado. E essa geração mais nova, que está saindo da faculdade agora para fazer documentário, de vinte e poucos anos, eles não viveram isso [...]. Então, a gente tem um olhar de busca, um olhar de análise sobre o passado, um olhar militante que eu acho bacana.

A cineasta santamariense Carolina Berger faz parte desta nova geração de cineastas e acredita que "Existe uma questão da sensibilidade feminina e isso está muito presente nas obras [...]" das realizadoras gaúchas. Ela foi a única exceção entre as entrevistadas a reconhecer que "[...] a mulher tem a particularidade de trabalhar com uma certa leveza e de respeitar o outro nesse encontro. Não se pode generalizar, mas em alguns casos, me parece que o homem é mais pragmático que a mulher”.

${ }^{18}$ As citações a seguir foram extraídas das entrevistas mencionadas. 


\section{Considerações finais}

Durante as entrevistas ficou evidente o quanto o documentário assume um caráter autoral para os realizadores gaúchos, que em geral escolhem os temas para seus filmes em função de suas curiosidades e inquietações. Spolidoro foi o único a reconhecer que a maioria dos seus filmes foi sob encomenda, que não teve muita interferência na escolha das temáticas, mas garantiu que "[...] teve roteiro, teve produtor, mas em todos eles eu consegui ter um lado autoral. Em todos eles eu consegui um projeto pessoal".

Divididos entre o universal e o regionalismo, os documentaristas gaúchos enfrentam o duplo desafio de, concomitantemente, produzir filmes que dialogam com as plateias de todo o Brasil e construam uma identidade para o documentário contemporâneo produzido no Estado. Os incentivos fiscais à cultura têm garantido a sobrevida desta produção, mas com algumas exceções, são raros os documentários que conseguiram transpor as fronteiras do sul do país.

O problema é ainda maior se levarmos em conta que a maioria destes filmes é desconhecida do próprio público das salas comerciais de cinema do Estado. É consenso entre os realizadores gaúchos que, para além da produção, é preciso garantir a distribuição/exibição do documentário brasileiro, e a televisão tem sido apontada como um dos principais canais de difusão para o gênero no país.

Com a aprovação da Lei 12.485, a Lei da TV Paga, que já está em vigor desde 12 de setembro de 2011, já se vê mudanças no cenário de exibição dos filmes nacionais, tanto documentários quanto ficções. Os canais classificados como "canais de espaço qualificado", que exibem predominantemente filmes, séries, animação e documentário, serão obrigados a dedicar 3h30min semanais de seu horário nobre à veiculação de conteúdos audiovisuais brasileiros. Hoje os itens obrigatórios estão sendo implementados de maneira progressiva. Mas o ato regulatório vai mais além ao definir que a metade, no mínimo, de toda esta produção a ser exibida deverá ser realizada por produtora brasileira independente, o que já vem estimulando o setor audiovisual no país. Nos próximos anos deve 
se desenhar novos caminhos para a produção de documentário no Brasil, resta saber qual será o comportamento das produtoras e dos documentaristas do Rio Grande do Sul a este cenário.

\section{Referências}

BECKER, T. Cinema gaúcho, uma breve história. Porto Alegre, RS: Movimento, 1986.

BERNARDET, J.C. Cinema brasileiro: propostas para uma história. São Paulo, SP: Cia das Letras, 2009.

MARUNO, G. R. (2008). Cinema documentário brasileiro contemporâneo: análise do Banco de Dados da Agência Nacional do Cinema (1994 a 2007). Dissertação de Mestrado, Programa de Pós-Graduação em Multimeios. UNICAMP, Campinas, São

Paulo, Brasil.

MERTEN, L. C. A aventura do cinema gaúcho. São Leopoldo, RS: UNISINOS, 2002.

SILVA NETO, A. L. Dicionário de filmes brasileiros: longa metragem. São Bernardo do Campo, SP: Ed. do Autor, 2009.

. Dicionário de filmes brasileiros: curta e média metragem (1897 a 2005). São Bernardo do Campo, SP: Ed. do Autor, 2005.

TRINDADE, T. N. A trajetória do documentário brasileiro: da produção à exibição. In: CÁNEPA, Laura; MULLER, Adalberto; SOUZA, Gustavo; SILVA, Marcel (Orgs.). Estudos de Cinema e Audiovisual Socine. v.12. São Paulo: Socine, 2011. p.268-281.

\section{Cássio dos Santos Tomaim}

Jornalista e doutor em História pela Universidade Estadual Paulista (Unesp) / Campus de Franca-SP, Brasil. Autor de artigos sobre documentário publicados em revistas cientificas é também autor do livro Janela da Alma: cinejornal e Estado Novo - fragmentos de um discurso totalitário (Annablume \& Fapesp, 2006). 